Збірник наукових праць Українського державного університету залізничного транспорту

УДК 656.073:656.222.4

ПОВЫШЕНИЕ ЭФФЕКТИВНОСТИ ОРГАНИЗАЦИИ МАЛОМОЩНЫХ
ВАГОНОПОТОКОВ ПРИ ИСПОЛЬЗОВАНИИ СИСТЕМЫ ВЗАИМОУВЯЗАННЫХ
ГРУППОВЫХ ПОЕЗДОВ

Н. А. Кекиш (БелГУТ)

ПІДВИЩЕННЯ ЕФЕКТИВНОСТІ ОРГАНІЗАЦІЇ МАЛОПОТУЖНИХ ВАГОНОПОТОКІВ ПІД ЧАС ВИКОРИСТАННЯ СИСТЕМИ ВЗАЕМОПОВ'ЯЗАНИХ ГРУПОВИХ ПОЇЗДІВ

\author{
Н. А. Кекіш (БілДУТ)
}

\title{
IMPROVING THE EFFICIENCY OF THE LOW-POWER CAR FLOWS USING THE SYSTEM OF INTERRELATED GROUP TRAINS
}

\author{
N. A. Kekish
}

Рассмотрены принцииь организачии вагонопотоков по системе взаимоувязанных групповых поездов и ее отличительные особенности. Проанализированы основные факторы, определяющие эффективность данной системы с точки зрения ускорения продвижения маломощных вагонопотоков. Приведены результаты сравнительной техникоэкономической оценки реализации предлагаемой системы организации на полигоне Белорусской железной дороги и даны рекомендации по перспективам ее применения на других полигонах.

Ключевые слова: организачия вагонопотоков, конфигурация полигона, маломощные потоки, групповые поезда, постоянное расписание, потенщиал транзитности.

Розглянуто принципи організації вагонопотоків по системі взаємопов'язаних групових поїздів і ї̈ відмінні риси. Проаналізовано основні фактори, щзо визначають ефективність даної системи з точки зору прискорення просування малопотужних вагонопотоків. Наведено результати порівняльної техніко-економічної оцінки реалізачії пропонованої системи організації на полігоні Білоруської залізниці та надано рекомендації щзодо перспектив ї̈ застосування на інших полігонах.

Ключові слова: організачія вагонопотоків, конфігурачія полігона, малопотужні потоки, групові поӥзди, постійний розклад, потенціал транзитності.

This paper is dedicated to considering the basic principles of the organization of car flows on the system of interrelated group trains and its distinctive features. The main factors determining the effectiveness of the system in terms of accelerating the promotion of low-power car flows and reduce transportation costs were analyzed. The use of regular schedule and taking into account the permanent factor of polygon configuration allows to create a transparent and stable system of organization.

The article stresses the need to clarify teminology. In particular, the quantification of the term "low-power flow" was made, as well as given an extended interpretation of the term "implementation of the transit potential" in the application to the proposed system. 
The article contains results of the comparative technical and economic evaluation of the implementation of the proposed system at the Belarusian Railways polygon and recommendations on the prospects for its use on other railways.

Keywords: Organization of car flows, polygon configuration, low-power flows, group trains, regular schedule, transit potential.

Введение. Система организации вагонопотоков является технологической основой, на которой базируется вся работа железнодорожного транспорта. Скорость доставки, себестоимость перевозок, эффективность использования инфраструктуры и подвижного состава, численность персонала и степень напряженности его работы, безопасность движения - все эти факторы, непосредственно определяющие конкурентоспособность железных дорог, зависят от выбранной системы организации вагонопотоков. Поэтому при решении вопросов, связанных с системой организации вагонопотоков, очень важен комплексный подход.

Разделение обширного союзного полигона на полигоны отдельных стран поставило перед железнодорожными администрациями сложную задачу адаптации системы организации к условиям и экономическим интересам своей страны с одновременным сохранением устойчивого технологического взаимодействия с соседними дорогами. Такая адаптация жизненно необходима для ряда дорог в связи с резким различием в размерах, конфигурации полигонов и структуре внутридорожного вагонопотока по мощности. Эти отличия делают невозможным применение с прежней эффективностью устоявшихся принципов организации, разработанных для других условий.

Анализ исследований. Система организации вагонопотоков, которая долгие годы использовалась на союзном полигоне, за последние годы претерпела существенные изменения на большинстве входивших в него железных дорог. Наиболее явной является тенденция к переходу на технологии постоянного расписания [1-4]. Эта тенденция является закономерной и отражает требования рынка по созданию транспортного продукта с приемлемыми для условий конкурентной среды параметрами перевозки. На РЖД она реализуется прежде всего для отправительской маршрутизации, что объясняется особенностями структуры вагонопотока [4]. Что касается зарубежного опыта применения постоянного расписания в грузовом движении, то особый интерес для полигонов масштабов Белорусской железной дороги или Укрзализницы представляет опыт небольших европейских стран, например Словакии [5], с их системой дискретного формирования и обращения грузовых поездов между выделенными станциями сети по постоянному расписанию. Однако эффективному применению такой технологии может препятствовать стабильно большая доля маломощных корреспонденций во внутридорожном потоке на ряде полигонов. В связи с этим закономерно существенное возрастание интереса к такой форме организации вагонопотоков, как групповые поезда. Однако подход к определению эффективности выделения групповых назначений в плане формирования [2] в целом остается прежним:

- традиционное позиционирование групповых поездов как средства организации вагонопотоков на направлениях с переломом массы и длины составов;

- нормирование в том или ином виде их массы и длины с незначительными отклонениями;

- методика расчета, базирующаяся на изначальном приоритете одногруппных назначений и сравнении по отдельным струям. 
Возможность формирования взаимоувязанных групповых поездов, обращающихся по постоянному расписанию, хотя и декларируется, но не дается четких рекомендаций по сфере применения этого способа организации, критериям выделения групповых назначений, количеству групп. В большинстве своем исследования ведутся в направлении организации групповых поездов в оперативных условиях [6-9]. Но для оперативной организации требуется основа в виде плана формирования, а существующие подходы к выделению групповых назначений не дают возможности эффективно применять предлагаемые схемы обращения групповых поездов.

Цель исследования. Целью настоящего исследования является разработка системы организации внутридорожных маломощных вагонопотоков на базе сети взаимоувязанных групповых поездов (ВГП), обращающихся по постоянному расписанию в пределах замкнутого разветвленного полигона. Учет особенностей конфигурации полигона и структуры обращающихся вагонопотоков призван адаптировать систему организации к конкретным условиям функционирования.

\section{Основная часть исследования.} Предлагаемая система ВГП имеет четко очерченную сферу применения, определяемую характеристиками полигона обращения и структурой вагонопотока. Она является комплементарной по отношению к существующей системе организации. В назначения, формируемые в рамках системы ВГП, включаются только корреспонденции вагонопотоков, обращающиеся в пределах полигона дороги и не охваченные назначениями межгосударственного сетевого плана формирования, отправительской и порожней маршрутизации.

Характеристики полигона обращения: замкнутый полигон с высокой степенью разветвленности по данной классификации [10], количеством технических станций на каждом направлении не менее 3, общим количеством технических станций не менее 8.
Структура вагонопотока: выделенный для обращения по данной системе внутридорожный вагонопоток должен иметь выраженное преобладание маломощных потоков (струй вагонопотока) в общей структуре (более $50 \%$ от их общего количества). Маломощные струи вагонопотока определенных назначений образуются при агрегации соответствующих маломощных корреспонденций. Следует отметить необходимость квантификации термина “маломощный поток". Этот термин употребляется достаточно давно и широко, но, как правило, без указания на количественные параметры, позволяющие классифицировать поток как маломощный. Исключением можно считать статью [9], где авторы определяют маломощное назначение как назначение с суточным вагонопотоком менее 6080 ваг/сут. Представляется целесообразным привязка верхней количественной границы маломощного потока к объекту исследования - параметрам существующей системы организации. В отношении выбранного для исследования полигона маломощным следует считать поток, среднесуточная мощность которого составляет менее $3 / 4$ мощности, достаточной для выделения сквозного одногруппного назначения при средней величине составов поездов, формируемых на данном полигоне в рамках технической маршрутизации. Снижение порога мощности потока на 1/4 призвано учесть возможные колебания величины состава при разных методах поездообразования (отправление по свободному расписанию с накоплением до унифицированной или дифференцированной массы/длины состава либо отправление по постоянному расписанию с накоплением до нормы массы/величины состава с установленным отклонением, как это описано в модели [11]). Например, предлагаемая система ВГП может быть применена к полигону соответствующей конфигурации, если более $50 \%$ струй вагонопотоков на назначения в пределах 
полигона дороги имеют мощность менее 45 ваг/сут при средней величине формируемых составов в 60 ваг.

Система ВГП является замкнутой, выделение групповых назначений и обращение поездов в ее рамках предусматривается только в пределах выбранного полигона. Замкнутый характер определяется возможностью влиять на продвижение отдельных категорий вагонопотоков через систему их организации, минимально затрагивая уже сформированную структуру взаимодействия между соседними железнодорожными администрациями.

Система ВГП базируется на принципах декомпозиции, повышения транзитности и взаимосвязи. Принцип декомпозиции отражает структуру сети для задачи организации выделенного вагонопотока. Все станции полигона классифицируются как узловые пункты трех уровней, а сам полигон разбивается на соответствующие районы тяготения. Механизм повышения транзитности в системе ВГП реализуется через максимально возможную для данного полигона и технологически приемлемую детализацию потока при формировании групповых назначений, переход вагонов из состава одного поезда в состав другого преимущественно через обмен групп, а также через жесткое нормирование времени нахождения вагонов на узловых пунктах и в районах тяготения. Принцип повышения транзитности диктует необходимость формировать групповые поезда с возможно большим, но целесообразным с технологической точки зрения количеством групп в составе. Например, для условий полигона Белорусской железной дороги это групповые поезда с максимальным количеством групп в составе, равным 4. Такое количество групп дает возможность большинству узловых пунктов первого уровня сформировать групповые назначения с максимальной возможностью реализации имеющегося потенциала транзитности.

Принцип взаимосвязи подразумевает два основных требования к организации обращения ВГП:

- структура формируемых групповых назначений должна обеспечивать технологическую возможность обмена групп с учетом действующих ограничений;

- должно быть разработано постоянное расписание обращения ВГП, учитывающее необходимость согласованного подвода поездов из районов тяготения, согласованного приема ВГП с пересекающихся направлений и согласованного их отправления на основе установленных норм простоя.

Для конкретного исследуемого полигона с использованием теории графов разрабатывается базовая модель организации вагонопотоков по системе ВГП, которая является основой плана формирования поездов в рамках данной системы. Математическая постановка задачи построения и корректировки базовой модели предусматривает формирование множества вариантов групповых назначений, их поэтапный отбор и взаимную увязку в масштабах полигона [12].

Методика построения и корректировки базовой модели имеет ряд принципиальных отличий от классической методики расчета плана формирования групповых поездов, используемой в инструктивных указаниях [2]:

1) пространственный характер расчета: предусмотрено формирование групповых поездов всеми выделенными узловыми пунктами первого уровня на полигоне, a не только на отдельных направлениях;

2) изначально заложенный приоритет групповых поездов: сфера применения системы ВГП, особенно в части структуры выделенного вагонопотока по мощности, предопределяет нецелесообразность в большинстве случаев формирования 
сквозных одногруппных поездов в рамках данной системы;

3) критерий выделения назначений: основным критерием выступает максимальная реализация потенциала транзитности для данной конфигурации полигона, а не мощность потока;

4) нормирование массы/длины составов или отдельных групп: в системе ВГП для составов определяется средняя величина состава, используемая для расчетов, а также широкий диапазон допустимой величины состава для целей оперативной работы по формированию групповых поездов. Нижняя граница этого диапазона может быть рассчитана по методике, приведенной в [13], в качестве верхней границы может быть использовано ограничение по силе тяги или ограничение по длине приемо-отправочных путей (в зависимости от условий конкретного полигона). Таким образом, система ВГП использует категорию групповых поездов, не предусмотренную существующими методиками: без постоянного веса групп, но с постоянным расписанием;

5) отсутствие "ядра": базовая технология ВГП предусматривает преимущественно не прицепку или отцепку, а перецепку групп, в том числе между несколькими согласованными поездами пересекающихся в данном узловом пункте направлений. При такой технологии и отсутствии жесткого нормирования массы/длины групп наличие "ядра" не является необходимым;

6) интенсивность обращения. В существующей системе организации вагонопотоков решающим критерием в определении интенсивности отправления поездов является мощность потока и некоторая установленная норма величины состава. В системе ВГП основными параметрами выступают норма времени на переход вагонов из состава в состав и норма времени на обслуживание района тяготения, рассчитанные из условия соблюдения установленной маршрутной скорости. Через эти параметры в системе ВГП изначально закладываются условия соблюдения срока доставки в той части логистической цепи доставки груза, в которой на этот процесс может повлиять система организации вагонопотоков в пределах выбранного полигона [14].

Реализация основных принципов построения системы ВГП позволяет:

- создать оптимальные условия для продвижения каждого типа вагонопотока в соответствии с его мощностью и характером следования. Комплементарность системы ВГП по отношению к существующей системе организации вагонопотоков сохраняет эффективный механизм организации для дальних мощных вагонопотоков (отправительская маршрутизация, выделение сквозных одногруппных назначений), в то же время обеспечивая продвижение дальних маломощных потоков на основе их поэтапной агрегации в масштабах полигона;

- создать минимальные равные с точки зрения потенциального соблюдения срока доставки условия для продвижения вагонопотоков вне зависимости от мощности каждой конкретной струи и от того, по каким участкам пролегает маршрут следования - малодеятельным или грузонапряженным;

- создать условия для максимальной прозрачности процесса перевозки как для клиента, так и для оперативной работы за счет существенного снижения уровня неопределенности в системе.

Эти преимущества одинаково важны как для интеграционной, так и для сепарационной модели организации работы железных дорог [15], что создает предпосылки к эффективному внедрению предлагаемой системы на полигонах с различными условиями взаимодействия между основными структурными подразделениями, обслуживающими перевозочный процесс.

Эффективность

организации маломощных вагонопотоков по системе 
ВГП прежде всего оценивается по ускорению их продвижения. При этом следует иметь в виду, что ускорение не является самоцелью. Его смысл лежит в достижении двух основных целей: соблюдение установленного срока доставки и ускорение оборота вагона.

При существующей системе организации вагонопотоков маломощные корреспонденции включаются, как правило, в участковые поезда. На полигонах с высокой степенью разветвленности и большим количеством технических станций на маршруте следования для дальних потоков это оборачивается длительными простоями на транзитных станциях из-за многочисленных переработок. Система ВГП дает возможность ускорить продвижение дальних маломощных потоков за счет двух основных факторов: лучшей реализации потенциала транзитности и сокращения продолжительности простоя на технических станциях (узловых пунктах).

Классическая трактовка понятия потенциала транзитности [16] в применении к организации вагонопотоков по системе ВГП требует расширения и уточнения. В трактовке понятия потенциала транзитности применительно к системе ВГП можно выделить два аспекта:

- дальность следования корреспонденций;

- характер проследования технической станции.

Поскольку для условий функционирования системы ВГП полигон представляется как замкнутый, то дальность следования корреспонденций при анализе реализации потенциала транзитности ограничивается пределами полигона. В качестве технических станций формирования, транзита и расформирования выступают соответствующие узловые пункты первого уровня направления. Различие с существующей системой иллюстрирует рис. 1. Если при существующей системе дальность следования корреспонденции вагонопотока равна расстоянию 1-5, то при системе ВГП станцией назначения считается станция 4.

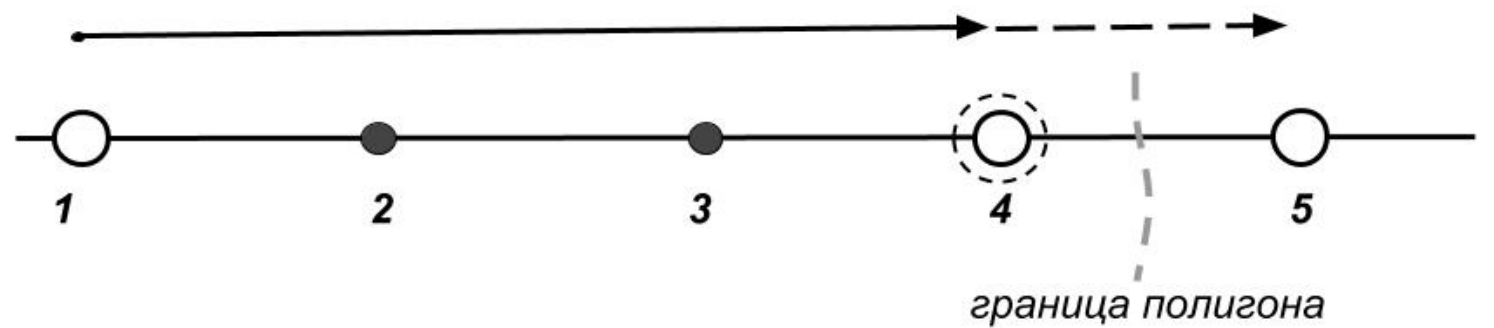

Рис. 1. Искусственное ограничение дальности следования корреспонденций для оценки реализации потенциала транзитности в системе ВГП

Классическая трактовка предусматривает реализацию потенциала транзитности при проследовании технической станции транзитом без переработки. В системе ВГП каждая корреспонденция вагонопотока, включенная в такие поезда, может проходить транзитную техническую станцию двумя способами: транзитом с обменом групп и транзитом с переработкой, причем, согласно принципам построения системы ВГП, преимущественно переход вагонов из состава одного поезда в состав другого должен проходить через обмен групп. Таким образом, для системы ВГП трактовка реализации потенциала транзитности должна быть 
расширена на проследование транзитом с обменом групп. Такое расширение правомерно с точки зрения:

1) сущности выполняемых технологических операций, т.к. имеет место отсутствие переработки вагонов, которые следуют через данную техническую станцию (в системе ВГП узловой пункт первого уровня) транзитом с обменом групп;

2) продолжительности выполняемых операций, т.к. простой при следовании транзитом с обменом групп, как правило, незначительно превышает простой при следовании транзитом без переработки и всегда существенно меньше простоя при следовании транзитом с переработкой.

Кроме того, для системы ВГП в связи с особенностями конфигурации полигонов, рекомендуемых для ее применения, может присутствовать такой тип проследования технической станции, как проследование без остановки. Возможность проследования узлового пункта первого уровня без остановки закладывается на этапе расчета базовой модели организации вагонопотоков по системе ВГП (плана формирования системы ВГП). Такой вариант проследования может быть квалифицирован как абсолютная реализация потенциала транзитности. При существующей системе организации вагонопотоков такой вариант также возможен. Для сквозных одногруппных назначений основным ограничителем по абсолютной реализации потенциала транзитности выступает конфигурация полигона, а именно расстояния между техническими станциями, определяющие схему оборота локомотивов.

Таким образом, для корректного сравнения системы организации вагонопотоков на базе ВГП с существующей системой организации вагонопотоков по критерию реализации потенциала транзитности следует учитывать особенности обращения ВГП и искусственно ограничивать дальность следования корреспонденции рамками выбранного полигона.

Под уровнем транзитности назначения понимается количество технических станций, которые корреспонденции вагонопотока, включенные в данное назначение, будут проходить транзитом без переработки [17], в расширенной трактовке - транзитом с обменом групп. В качестве назначения, для которого оценивается уровень транзитности, в системе ВГП выступает назначение каждой отдельной группы в групповом составе. В качестве технической станции, относительно которой оценивается реализация потенциала транзитности, рассматривается транзитный узловой пункт первого уровня. Узловые пункты первого уровня, выступающие как станции отправления и назначения корреспонденции вагонопотока в пределах полигона, потенциально не могут быть проследованы транзитом, поэтому при расчете уровня транзитности не учитываются.

Если говорить о степени реализации потенциала транзитности, то можно выделить следующие категории назначений, в которые могут включаться корреспонденции вагонопотоков (рис. 2):

- назначения, не обладающие потенциалом транзитности $(A) . \mathrm{He}$ обладают потенциалом транзитности назначения на соседнюю техническую станцию (узловой пункт первого уровня) на соответствующем направлении. В данном случае потенциал транзитности не реализуется по объективным причинам, обусловленным характеристиками самой корреспонденции;

- назначения, частично реализующие имеющийся потенциал транзитности $(B)$. При включении корреспонденции вагонопотока в такие назначения часть транзитных узловых пунктов первого уровня на маршруте следования он проходит без переработки (с обменом групп), а часть - с переработкой; 
- назначения, полностью реализующие потенциал транзитности $(C)$. При включении корреспонденции вагонопотока в такие назначения все транзитные узловые пункты первого уровня на маршруте следования он проходит без переработки (с обменом групп);
- назначения, полностью не реализующие потенциал транзитности $(D)$. При включении корреспонденции вагонопотока в такие назначения все транзитные узловые пункты первого уровня на маршруте следования он проходит с переработкой.

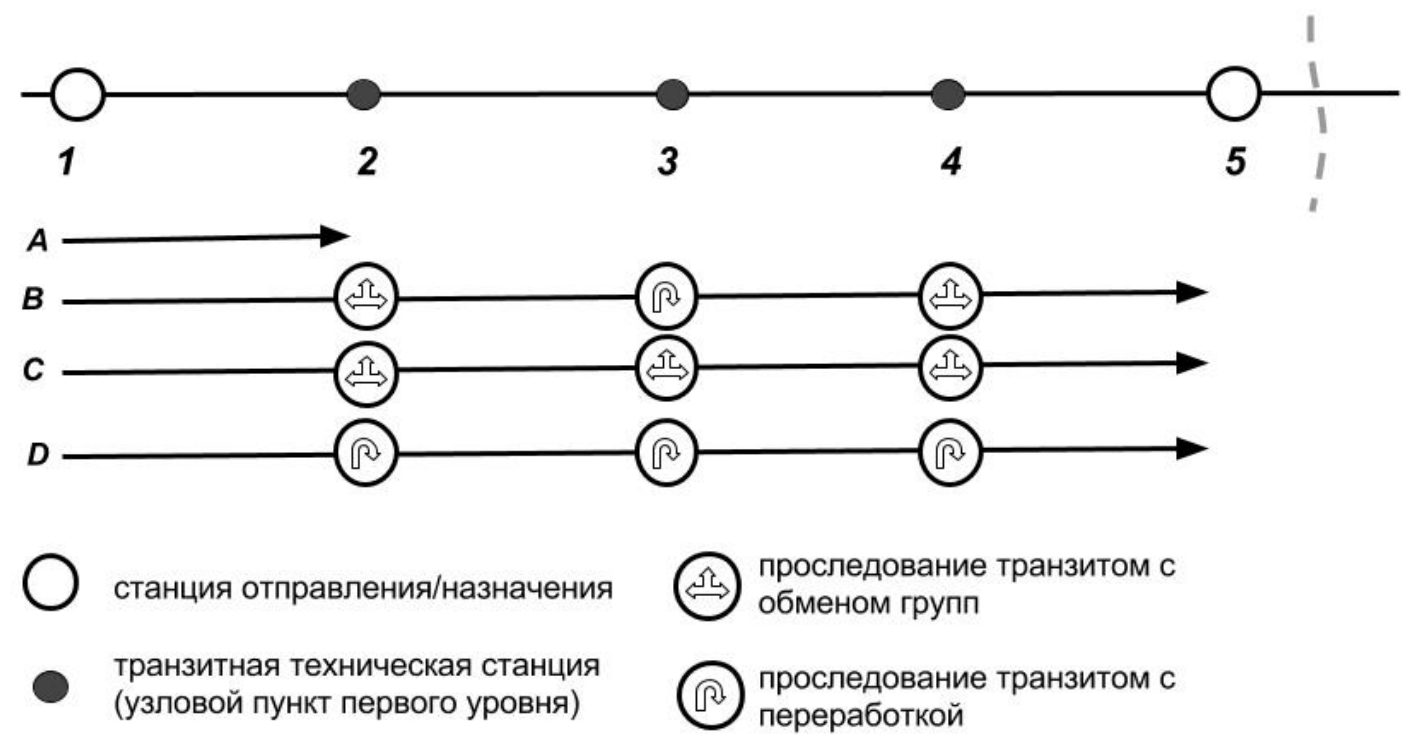

Рис. 2. Варианты реализации потенциала транзитности различными категориями назначений

Во всех случаях маршрут следования для системы ВГП ограничен масштабами полигона.

Сокращение продолжительности простоя на технических станциях (узловых пунктах первого уровня) достигается как за счет уменьшения количества переработок вагонов дальних назначений в связи с лучшей реализацией потенциала транзитности, так и за счет жесткого нормирования продолжительности нахождения вагонов на узловых пунктах. Происходит не только замена более длительного простоя транзитного вагона с переработкой значительно менее длительным простоем при обмене групп, но и сокращение продолжительности простоя с переработкой.
Для проведения сравнительной оценки ускорения продвижения маломощных вагонопотоков за счет повышения уровня транзитности формируемых назначений на основании данных о фактических вагонопотоках за 2016 г., полученных из АСОВ “Динамическая карта", была сформирована итоговая модель организации вагонопотоков по системе ВГП для полигона Белорусской железной дороги (ИМ). Эта модель была сопоставлена с моделью организации внутридорожного вагонопотока по существующему плану формирования (ПФ).

Сопоставление производилось для той части вагонопотока, которая может быть охвачена системой ВГП. Дальность следования корреспонденций в обоих вариантах была ограничена рамками 
полигона. В качестве технических станций, относительно которых для обоих вариантов определялась степень реализации потенциала транзитности, были выбраны 17 основных станций Белорусской железной дороги, которые в системе ВГП выступали как узловые пункты первого уровня. Проследование технических станций, находящихся на маршруте следования между выделенными узловыми пунктами первого уровня, в данном расчете не учитывалось.

Сравнивая достигнутый уровень транзитности назначений, можно отметить и количественное, и качественное преимущество системы ВГП по этому показателю (рис. 3).

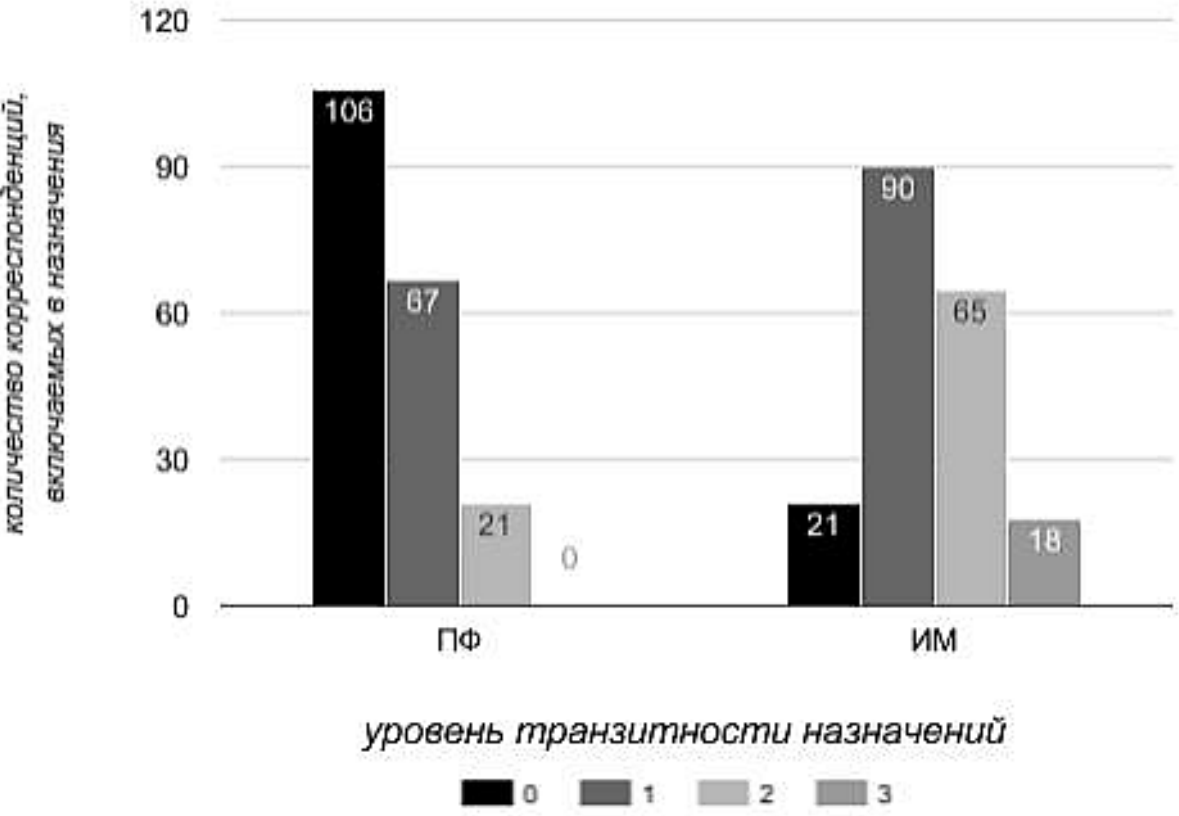

Рис. 3. Уровень транзитности назначений при существующей системе организации и системе ВГП

Количественное преимущество определяется ростом количества корреспонденций, включаемых в назначения первого и второго уровня транзитности. Количественное изменение видно по появлению назначений третьего уровня транзитности, отсутствующих в существующей системе. Преобладающая часть вагонопотока в условиях предлагаемой системы включается в назначения, полностью или частично реализующие имеющийся потенциал транзитности. При существующей системе наблюдается обратная картина: из-за преобладания участковых назначений в структуре плана формирования большая часть рассматриваемого вагонопотока включается в назначения, полностью не реализующие имеющийся потенциал транзитности (рис. 4).

Повышение транзитности вагонопотоков при реализации системы ВГП положительно сказывается на ускорении их продвижения, что убедительно демонстрируют сравнительные графики маршрутной скорости (рис. 5). Следует отдельно отметить, что при существующей системе с нарушением установленной 
Збірник наукових праць Українського державного університету залізничного транспорту

маршрутной скорости на части маршрута между узловыми пунктами первого уровня следует $37 \%$ от общего количества корреспонденций.
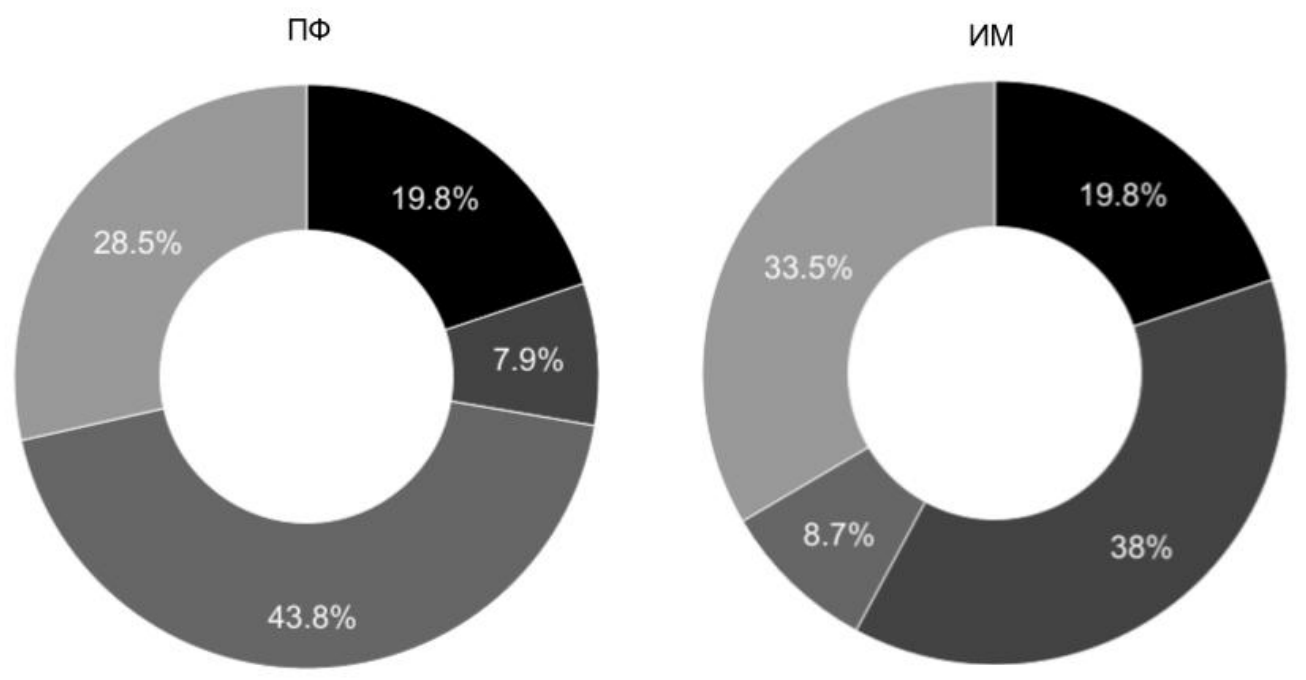
назначения, не обладающие потенциалом транзитности
- назначения, полностью реализующие потенциал транзитности

$$
\begin{aligned}
& \text { назначения, полностью не реализующие } \\
& \text { потенциал транзитности } \\
& \text { назначения, частично реализующие потенциал } \\
& \text { транзитности }
\end{aligned}
$$

В наибольшей степени при реализации системы ВГП закономерно ускоряется продвижение дальних корреспонденций (рис. 6).

Рис. 4. Распределение выделенного вагонопотока по назначениям с разной степенью реализации потенциала транзитности

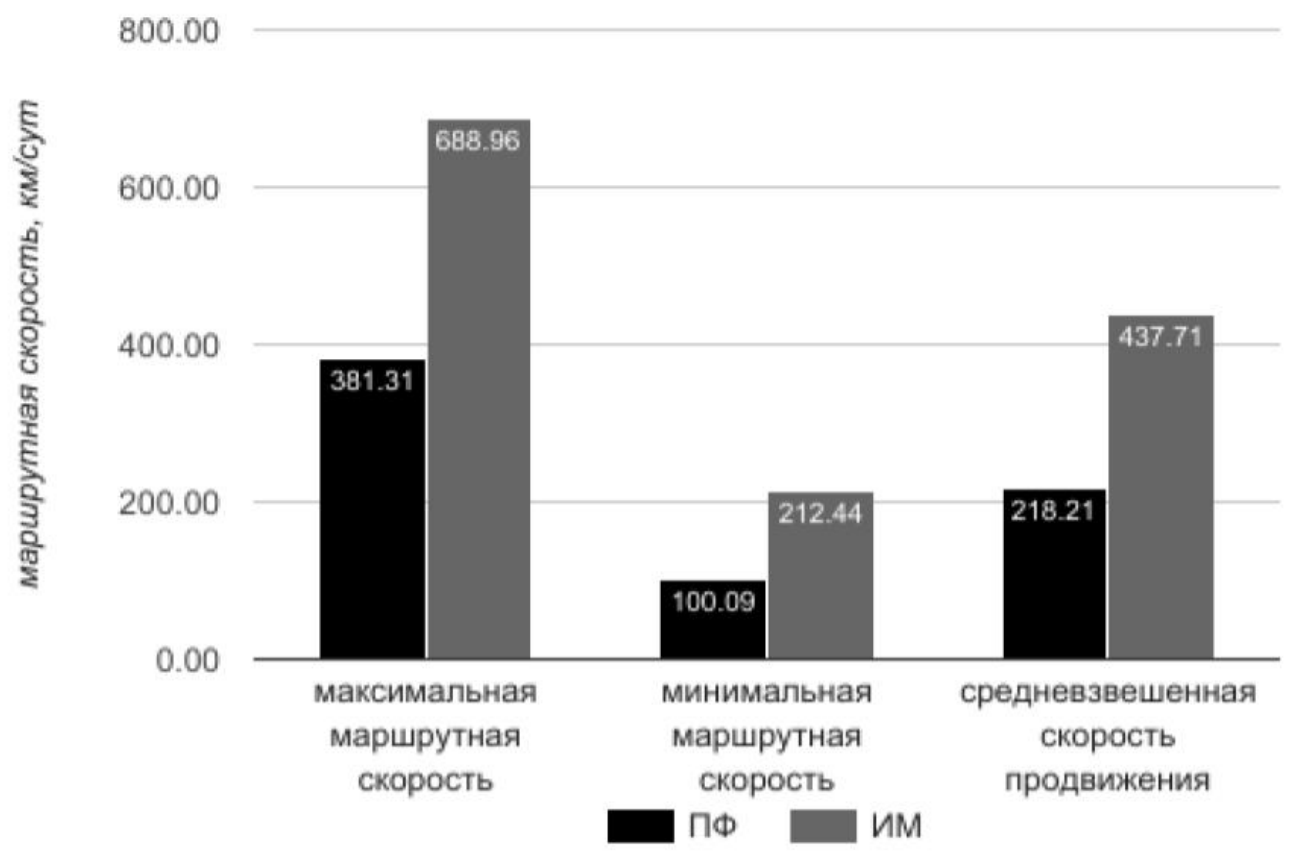

Рис. 5. Сравнительные показатели маршрутной скорости 


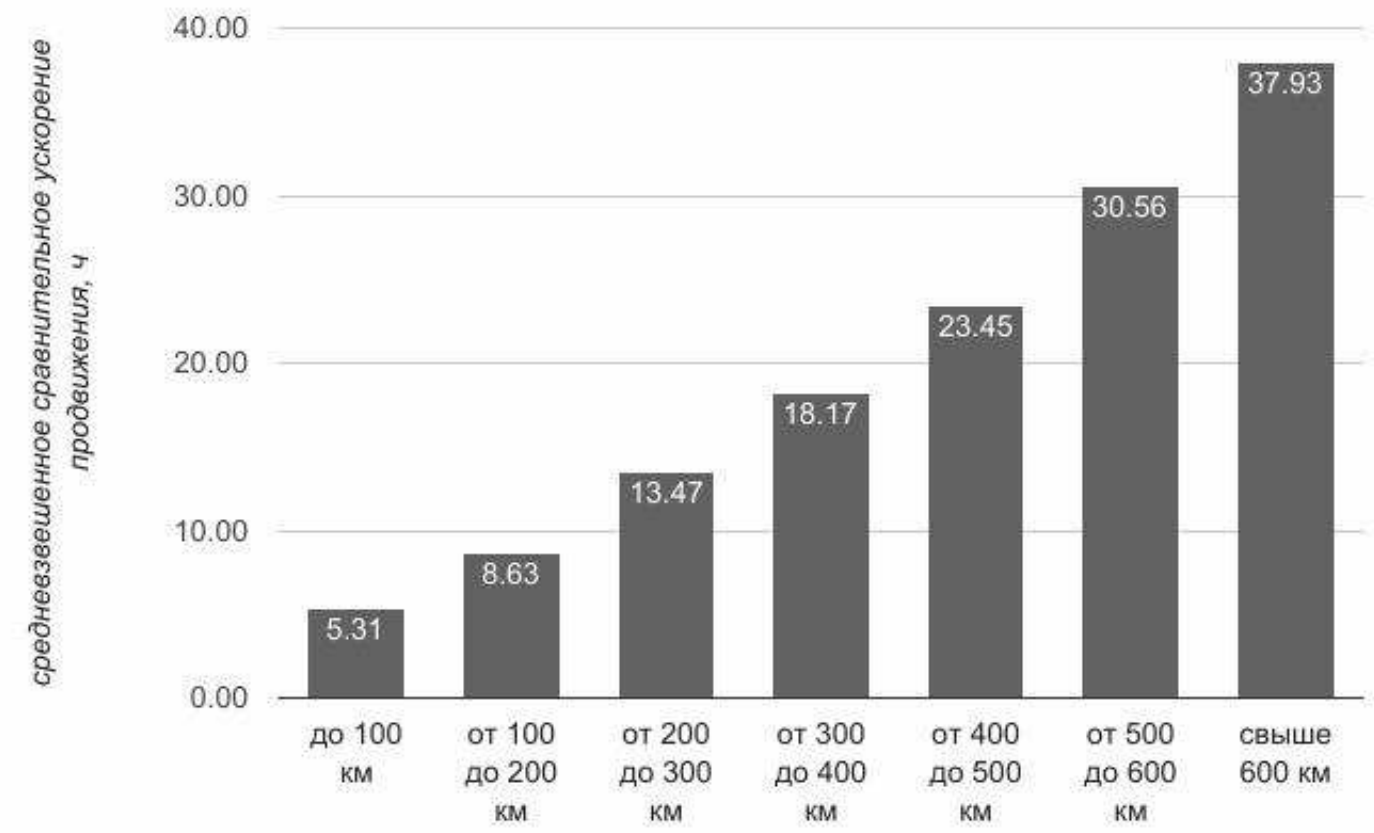

дальность следования корреспонденции вагонопотока, км

Рис. 6. Ускорение продвижения корреспонденций вагонопотоков в зависимости от дальности следования при реализации системы ВГП

При данном расчете были выделены следующие основные факторы сокращения затрат при организации вагонопотоков по системе ВГП (по сравнению с существующей системой организации):

- ускорение оборота вагона, обеспечивающее снижение затрат на простой вагонов на $64 \%$, суммарных затрат на перевозки для выделенной части вагонопотока - на 18-27 \%;

- выравнивание размеров движения в четном и нечетном направлении за счет установления минимальной интенсивности отправления (снижение затрат на дополнительный пробег локомотивов из-за разности размеров движения на $71 \%$ );

- перераспределение объема переработки между станциями (снижение общего объема переработки на $10 \%$ с повышением эффективности использования сортировочных мощностей в целом по полигону).

\section{Выводы и перспективы} дальнейшего развития. Предлагаемая система ВГП является эффективным инструментом организации маломощных внутридорожных вагонопотоков на полигонах с высокой степенью разветвленности. Обращение по постоянному расписанию, учет конфигурации полигона и заложенные в основу расчета принципы повышения транзитности и соблюдения срока доставки позволяют добиться существенного ускорения продвижения маломощных вагонопотоков. Экономическая целесообразность применения данной системы определяется прежде всего уровнем снижения затрат, связанных с ускорением оборота вагона.

Система адаптирована для применения на полигонах с двумя основными признаками: высокая степень разветвленности по конфигурации и преобладание маломощных потоков в общей структуре. Кроме исследованного в работе полигона Белорусской железной дороги, по критерию конфигурации в качестве перспективных для внедрения системы могут рассмат- 
риваться полигоны Дальневосточной, Забайкальской, Свердловской, СевероКавказской, Юго-Восточной железных дорог (среди полигонов РЖД), а также объединенный полигон Львовской и ЮгоЗападной дорог Укрзализницы.

\section{Список использованных источников}

1. Шаров, В. А. Интегрированная технология управления движением грузовых поездов по расписанию [Текст] / В. А. Шаров, А. Ф. Бородин // Железнодорожный транспорт. - 2011. - № 8. - C. 11-22.

2. Методические рекомендации по организации вагонопотоков на Белорусской железной дороге [Текст]: утв. приказом № 772 НЗ первого заместителя начальника Белорусской железной дороги 30.12.2013. - Минск, 2014. - 324 с.

3. Інструктивні вказівки 3 організації вагонопотоків на залізницях України [Текст]: №1028 - Ц3: затв. наказом Укрзалізниці 29.12.2004. - К.: ТОВ «Швидкий рух», 2005. - 100 с.

4. Апатцев, В. И. К реализации комплексной программы поэтапного перехода на организацию движения грузовых поездов по расписанию на российских железных дорогах [Текст] / В. И. Апатцев, В. А. Шаров // Наука и техника транспорта. - 2011. - № 3. - С. 6972.

5. Masek, J. Innovative Methods of Improving Train Formation in Freight Transport [Text] / J. Masek, J. Camaj, E. Nedeliakova // International Journal of Mechanical, Aerospace, Industrial, Mechatronic and Manufacturing Engineer. - 2015. - Vol. 9, Issue 11. - P. 1936-1939.

6. Прохорченко, А. В. Удосконалення технології роботи полігона мережі на основі організації групових поїздів за жорстким графіком руху [Текст] / А. В. Прохорченко // Зб. наук. праць Укр. держ. акад. залізнич. трансп. - Харків: УкрДАЗТ, 2010. - Вип. 114. - С. 196200.

7. Бутько, Т. В. Формалізація технології організації групових поїздів оперативного призначення [Текст] / Т. В. Бутько, А. В. Прохорченко, А. М. Киман // Східно-Свропейський журнал передових технологій. - 2015. - Т. 4, № 3 (76). - С. 38-43.

8. Киман, А. М. Удосконалення технології організації групових поїздів оперативного призначення на основі синхронізації графіка руху на станціях обміну груп вагонів [Текст] / А. М. Киман // Інформаційно-керуючі системи на залізничному транспорті. - 2015. - № 5. C. $48-51$.

9. Лаврухін, О. В. Формування автоматизованої технології просування групових поїздів оперативного призначення [Текст] / О. В. Лаврухін, О. М. Костєнніков, А. М. Киман // Транспортні системи та технології перевезень. - 2016. - Вип. 12. - С. 51-57.

10. Кудрявцев, В. А. Закономерности составообразования на сортировочных станциях при отправлении поездов по твердому графику движения [Текст] / В.А. Кудрявцев, А.А. Светашев // Известия ПГУПС. - 2015. - №2. - С. 5-14.

11. Кекиш, Н. А. Конфигурация полигонов железных дорог [Текст] / Н. А. Кекиш // Мир транспорта. - 2011. - №2(35). - С. 98-103.

12. Кекиш, Н. А. Математическая постановка задачи формирования базовой модели организации вагонопотоков по системе взаимоувязанных групповых поездов между узловыми пунктами первого уровня [Текст] / Н. А. Кекиш // Вестник БелГУТа: Наука и транспорт. - 2007. - № 1-2 (14-15). - С. 99-103.

13. Кудрявцев, В. А. Определение оптимальной нормы состава грузового поезда [Текст] / В. А. Кудрявцев, В. В. Волчанинов, Ю. А. Кокшаров // Известия ПГУПС. - 2004. №2. - C. 19-28. 
14. Кекиш, Н. А. Организация вагонопотоков по системе взаимоувязанных групповых поездов: проблемы и пути решения [Текст] / Н. А. Кекиш // Вестник БелГУТа: Наука и транспорт. - 2009. - № 1(18). - С. 34-37.

15. Jaržemskis, A. The Differences in Efficiency Measurment: The Case of European Raylways [Text] / A. Jaržemskis, V. Jaržemskis // Transport and Telecommunication. - 2014. Vol. 15, № 2. - P. 151-163.

16. Аветикян, А. А. Потенциал транзитности вагонопотоков [Текст] / А. А. Аветикян. М.: Транспорт, 1981. - 191 с.

17. Ерофеев, А. А. Повышение транзитности в системе организации вагонопотоков [Текст] / А. А. Ерофеев // Наука и прогресс транспорта: Вестник Днепропетровского национального университета железнодорожного транспорта. - 2008. - № 21. - С. 228-232.

Кекіш Наталія Анатоліївна, молодший науковий співробітник кафедри вишукування та проектування колії Білоруського державного університету транспорту. Тел.: (+37529) 682-66-93. E-mail: natalia.kekish@ gmail.com.

Kekish Natalia, Research Associate of the Department "Surveying and Design of Roads" of the Belarusian State University of Transport. Tel.: (+37529) 682-66-93. E-mail: natalia.kekish@ gmail.com.

Стаття прийнята 15.02.2017 p. 